\title{
Metabolism and thermoregulation in the Mongolian gerbil Meriones unguiculatus
}

\author{
Dehua WANG, Yushan WANG and Zuwang WANG
}

Wang D., Wang Y. and Wang Z. 2000. Metabolism and thermoregulation in the Mongolian gerbil Meriones unguiculatus. Acta Theriologica 45: 183-192.

Oxygen consumption, thermal conductance and body temperature of Meriones unguiculatus (Milne-Edwards, 1867) were measured at a temperature range from 5 to $40^{\circ} \mathrm{C}$. The lowest mean metabolic rate (BMR) was $2.13 \pm 0.14 \mathrm{mlO}_{2} \mathrm{~g}^{-1} \cdot \mathrm{h}^{-1}$, which is higher than the predicted values based on their body mass. The thermal neutral zone (TNZ) was 26 to $38^{\circ} \mathrm{C}$. Mean body temperature below the TNZ was $38.4 \pm 0.5^{\circ} \mathrm{C}$. Mean thermal conductance below the TNZ was $0.179 \pm 0.037 \mathrm{mlO}_{2} \mathrm{~g}^{-1} \cdot \mathrm{h}^{-1} \cdot{ }^{\circ} \mathrm{C}^{-1}$, which is also higher than predicted values based on their body mass. Thermoregulatory characteristics of Mongolian gerbils are very different from that found in arid-adapted small mammals. The extreme severe climate perhaps is the main selective force faced by Mongolian gerbils during their evolution with their macroenvironments.

Institute of Zoology, Chinese Academy of Sciences; State Key Laboratory of Integrated Management for Pest Insects and Rodents; 19 Zhongguancun Road, Haidian, Beijing 100080, People's Republic of China; e-mail: wangdh@panda.ioz.ac.cn

Key words: Meriones unguiculatus, basal metabolic rate, thermal conductance, thermoregulation

\section{Introduction}

The Mongolian gerbil Meriones unguiculatus (Milne-Edwards, 1867) is a small cricetid rodent native to the desert and semiarid regions of Mongolia and northern China (Walker 1968). Robinson (1959) first measured the metabolic rate of $M$. unguiculatus and reported that this species showed a relative wide thermal neutral zone (TNZ; from 30 to $40^{\circ} \mathrm{C}$ ) and possessed a great tolerance for heat. Thus he concluded that this species had a greater capacity for thermoregulation than other desert rodent species. Luebbert et al. (1979) studied the temperature acclimation for this species and found similar properties in many metabolic aspects, but a narrow TNZ.

Most studies on thermoregulation of Mongolian gerbils were on laboratory-bred individuals, and the whole laboratory population of gerbils was raised from only 11 pairs imported to USA from China in 1954 (Robinson 1959, Weiner and Górecki 1981). Weiner and Górecki (1981) studied the metabolic characteristics of wild gerbils from Mongolia and found that $M$. unguiculatus showed some desert-adaptive features such as a narrow TNZ (about $15-18^{\circ} \mathrm{C}$ ) and a steep thermoregulatory 
curve. In their study temperature range was about 8 to $25^{\circ} \mathrm{C}$, and they reported that $25^{\circ} \mathrm{C}$ was the lethal temperature for those gerbils. It seems that there existed a marked difference in the ecophysiological properties between wild and laboratory populations of $M$. unguiculatus.

Because of the conflicting results reported in literature for Mongolian gerbils, it is necessary and very interesting to study the characteristics of thermal biology for this species. In this study we measured the metabolism of $M$. unguiculatus that were newly caught in the temperate grassland of Inner Mongolia. Climate characteristics of Mongolian desert (ie a hot summer and a long, cold and dry winter) differ from those of hot deserts. Therefore, we predicted that (1) Mongolian gerbils living here may show some different metabolic responses compared with those found in hot desert rodents, and (2) because of the different conditions between field and laboratory, the newly captured gerbils may show different metabolic properties from laboratory-bred gerbils.

\section{Material and methods}

\section{Animals}

Eight adult Mongolian gerbils (4 males, 4 females) were live-trapped in the semiarid steppe at Xilinhot, Inner Mongolia, China, in spring (April) 1998. The mean body mass was $58.1 \pm 8.7$ (SD) g. The fluctuation of ambient temperature between day and night is great. In summer the temperature range was from $3{ }^{\circ} \mathrm{C}$ during the night to $52^{\circ} \mathrm{C}$ during the day in the sun (Agren et al. 1990). The annual mean temperature is $-0.4^{\circ} \mathrm{C}$, average monthly air temperature in the coldest month (January) is $-22.3^{\circ} \mathrm{C}$, while $18.8^{\circ} \mathrm{C}$ during the warmest month (July). The yearly range is -47.5 to $35.3^{\circ} \mathrm{C}$. There are four months (December through March) in which the extreme minimum ambient temperature is below $-40^{\circ} \mathrm{C}$. In April when animals were trapped, the mean ambient temperature is $2.6^{\circ} \mathrm{C}$, the maximum ambient temperature is $28.8^{\circ} \mathrm{C}$ and the minimum is $-29.2^{\circ} \mathrm{C}$. Annual precipitation is $350 \mathrm{~mm}$ and the plant growth period is about $150-180$ days (Chen 1988).

After capture, the body mass $(\mathrm{Mb})$, sex and reproductive state of the animals were examined and recorded in the laboratory. Animals were kept in large cages $(47.5 \times 35 \times 20 \mathrm{~cm})$ under natural photoperiod (ca 14L : 10D) and temperature $\left(5-18^{\circ} \mathrm{C}\right)$ and were fed laboratory rat chow pellets for about a week. Food and water were supplied ad lib.

\section{Measurement procedure}

Oxygen consumption rates were measured using the Kalabukhov-Skovortsov closed-circuit respirometer according to Górecki (1975). Temperatures inside the animal chambers submerged in a water both were measured and maintained constant to whin $1^{\circ} \mathrm{C}$. Metabolic chamber size was $3.6 \mathrm{dm}^{3} . \mathrm{Mb}$ and rectal temperatures $(\mathrm{Tb})$ of animals were recorded before and after each experiment. $\mathrm{Tb}$ was measured by a digital thermometer (Beijing Normal University Instruments Co.) in rectum at depth of $3 \mathrm{~cm}$.

Metabolic rate measurements were made over a temperature range from 5 to $40^{\circ} \mathrm{C}$ and each measurement lasted for $40 \mathrm{~min}$ after the animals had been in the metabolic chamber for about $1 \mathrm{~h}$. Before each experiment food was witheld 3 hours to minimize the specific dynamic action of food and gerbils were weighed to the nearest $0.1 \mathrm{~g}$. Records of oxygen consumption due to animal's act.vity in the chamber were discarded when computing the metabolic rate of each individual.

All measurements were made daily between $08.30 \mathrm{~h}$ and $19.00 \mathrm{~h}$. Metabolic rates were expressed as $\mathrm{mlO}_{2} \cdot \mathrm{g}^{-1} \cdot \mathrm{h}^{-1}$ and corrected to STP conditions. Obviously pregnant or lactating animals were not used in the experiments. 


\section{Thermal conductance}

Overall thermal conductance $\left(\mathrm{C}, \mathrm{mlO}_{2} \cdot \mathrm{g}^{-1} \cdot \mathrm{h}^{-1} \cdot{ }^{\circ} \mathrm{C}^{-1}\right)$ was calculated at temperatures below the thermal neutral zone using the formula:

$$
\mathrm{C}=\mathrm{MR} /(\mathrm{Tb}-\mathrm{Ta})
$$

where MR is metabolic rate (in $\mathrm{mlO}_{2} \cdot \mathrm{g}^{-1} \cdot \mathrm{h}^{-1}$ ), Tb is body temperature (in ${ }^{\circ} \mathrm{C}$ ), and $\mathrm{Ta}$ is ambient temperature (in ${ }^{\circ} \mathrm{C}$ ). This formula has been suggested by McNab (1980) as well as Bradley and Deavers (1980) for calculating conductance at any given ambient temperature.

\section{Statistics}

Data were analyzed using SPSS package (1998). Differences between groups were determined by Student's $t$-test and $p<0.05$ was taken to be statistically significant. Regression equations were determined by the method of least squares using all data points. All values were presented as mean $\pm \mathrm{SD}$

\section{Results}

\section{Body temperature (Tb)}

Fig. 1 shows the changes of $\mathrm{Tb}$ with ambient temperature (Ta). Mean $\mathrm{Tb}$ was $38.8 \pm 0.9^{\circ} \mathrm{C}$ after experiments and ranged from a mean of $38.2 \pm 0.3^{\circ} \mathrm{C}$ at $28^{\circ} \mathrm{C}$ to $41.0 \pm 1.2^{\circ} \mathrm{C}$ at $40^{\circ} \mathrm{C}$. Tbs were fairly constant between 5 and $32^{\circ} \mathrm{C}$ (ie $38.4 \pm 0.5^{\circ} \mathrm{C}$ ), but increased above $34^{\circ} \mathrm{C}$. At $40^{\circ} \mathrm{C}, 25 \%$ of the gerbils died at the end of metabolic determination.

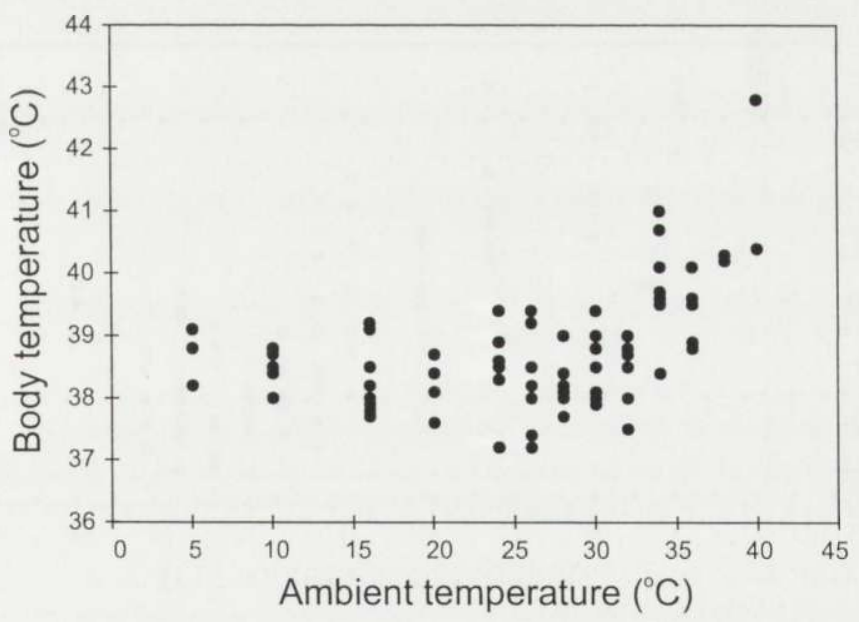

Fig 1. Body temperatures of Mongolian gerbil Meriones unguiculatus at different ambient temperatures. $n=8$. 


\section{Metabolic rate}

Metabolic rates of gerbils measured over the Ta range from 5 to $40^{\circ} \mathrm{C}$ are shown in Fig. 2. Metabolic rates were kept stable from 26 to $38^{\circ} \mathrm{C}$. Although there was no significant difference for metabolic rates between 24 and $26^{\circ} \mathrm{C}$, the difference between 24 and $36^{\circ} \mathrm{C}$ was significant $(p<0.01)$. Iterative fitting method also showed that $26^{\circ} \mathrm{C}$ is the "turning point" of the line between metabolic rates and Ta. Thus, $26^{\circ} \mathrm{C}$ was thought to be the lower critical temperature. Above $38^{\circ} \mathrm{C}$, metabolic rate significantly increased $(p<0.05)$ and was regarded as the upper critical temperature. Thus the thermal neutral zone (TNZ) during the present study extended from 26 to $38^{\circ} \mathrm{C}$. Metabolic rates within this temperature zone are regarded as basal metabolic rate (BMR). The mean BMR was $2.13 \pm 0.14 \mathrm{mlO}_{2} \cdot \mathrm{g}^{-1} \cdot \mathrm{h}^{-1}$, ie $172 \%$ and $163 \%$ of the values predicted by Kleiber $\left(1961\right.$ : $\mathrm{BMR}=3.42 \mathrm{M}^{-0.25}$ for eutherian mammals, where $M$ is body mass in $g$ ) and Hayssen and Lacy (1985: $\mathrm{BMR}=4.98 \mathrm{M}^{-0.33}$ for rodent species), respectively.

Below the TNZ, metabolic rates increased with decreasing Ta (Fig. 2), the relationship between resting metabolic rates (RMR) and Ta is described by:

$\mathrm{RMR}\left(\mathrm{mlO}_{2} \cdot \mathrm{g}^{-1} \cdot \mathrm{h}^{-1}\right)=5.47( \pm 0.188)-0.108( \pm 0.010) \mathrm{Ta}(r=-0.9827$, $p<0.001)$.

\section{Thermal conductance $(\mathrm{C})$}

The variations of overall thermal conductance with Ta for gerbils are shown in Fig. 3 . Below the TNZ, the average $\mathrm{C}$ was $0.179 \pm 0.037 \mathrm{mlO}{ }_{2} \cdot \mathrm{g}^{-1} \cdot \mathrm{h}^{-1} \cdot{ }^{\circ} \mathrm{C}^{-1}$, which is $137 \%$ and $133 \%$ of that predicted by Herreid and Kessel $\left(1967: \mathrm{C}=1.0 \mathrm{M}^{-0.50}\right.$, where $\mathrm{M}$ is body mass in $\mathrm{g}$ ) and Bradley and Deavers (1980: $\mathrm{C}=0.76 \mathrm{M}^{-0.43}$ ), respectively, based on body mass.

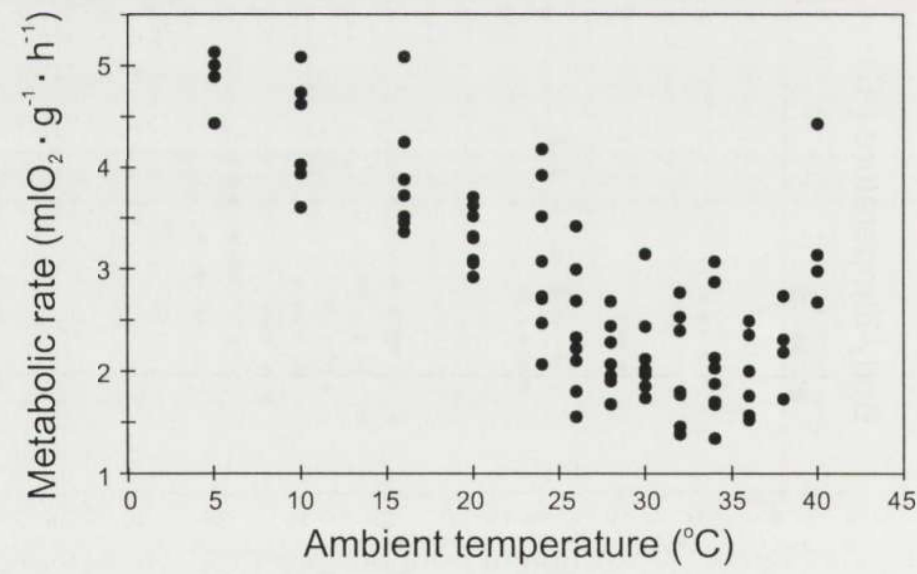

Fig. 2. Relationship between metabolic rates and ambient temperatures in Mongolian gerbil Meriones unguiculatus. $n=8$. 


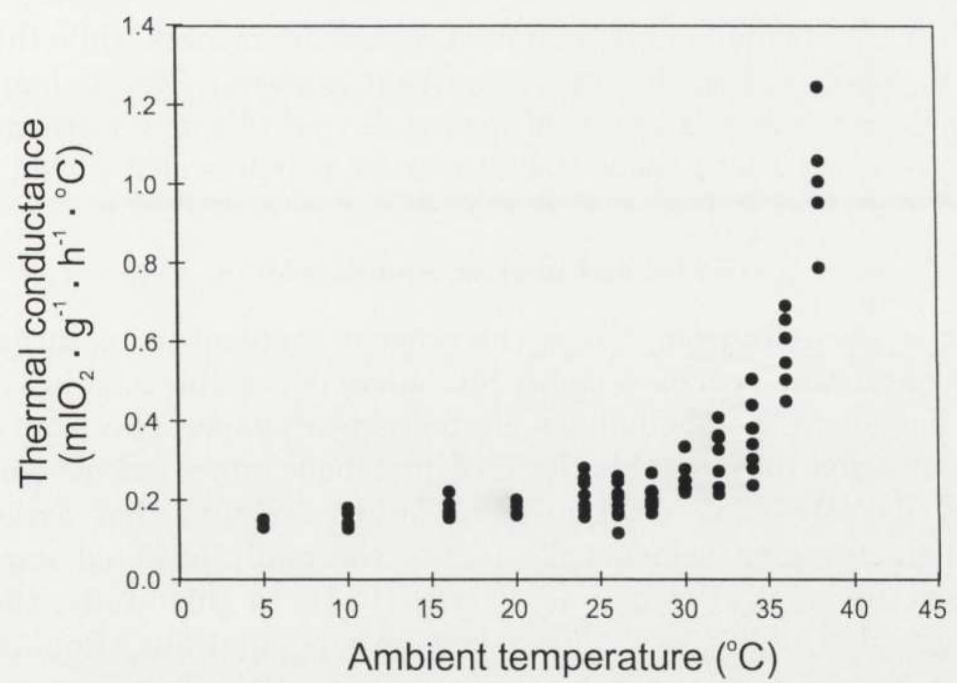

Fig. 3. Thermal conductance of Mongolian gerbil Meriones unguiculatus at different ambient temperatures. $n=8$.

Within and above the TNZ, C increased significantly with increasing Ta, and sharply increased from $38^{\circ} \mathrm{C}\left(1.01 \pm 0.17 \mathrm{mlO}_{2} \cdot \mathrm{g}^{-1} \cdot \mathrm{h}^{-1} \cdot{ }^{\circ} \mathrm{C}^{-1}\right)$, reaching $5.89 \pm 2.91$ $\mathrm{mlO}_{2} \cdot \mathrm{g}^{-1} \cdot \mathrm{h}^{-1} \cdot{ }^{\circ} \mathrm{C}^{-1}$ at $40^{\circ} \mathrm{C}$ (not shown in Fig. 3 ).

\section{Discussion}

The following characteristics are typical for desert animals: (1) a relatively low BMR, (2) a steep thermoregulatory curve, (3) a narrow and hard-to-define thermoneutral zone (TNZ), and (4) a high lower critical temperature (Weiner and Górecki 1981, Degen 1997). Webb and Skinner (1996) stated that gerbils (subfamily Gerbillinae) have low BMR and average minimum thermal conductance when compared to other rodents and other mammals of the same body mass. In this study, Mongolian gerbils had neither a lowered BMR and thermal conductance nor a narrow TNZ but they do inhabit a semiarid environment.

\section{Body temperature (Tb)}

Within the TNZ most desert rodents have a $\mathrm{Tb}$ of $37^{\circ} \mathrm{C}$ or lower, whereas most nondesert rodents have a $\mathrm{Tb}$ of $37^{\circ} \mathrm{C}$ or above. Lower $\mathrm{Tbs}$ of desert species represents an increased ability to maintain a small temperature differential during periods of high Ta (Bradley and Yousef 1972). But, for adult Mongolian gerbils kept below the TNZ, mean resting body temperatures were $38.4^{\circ} \mathrm{C}$. Luebbert et al. (1979) reported that laboratory-bred Mongolian gerbils could maintain their Tbs above $38^{\circ} \mathrm{C}$ over a wide Ta range. 
A rise in the $\mathrm{Tb}$ of small desert mammals often commences while the animal is still within its TNZ, and in this way some heat is stored. This is more common among the larger of the small diurnal mammals and in some nocturnal rodents. Mongolian gerbils increased their Tbs from $34^{\circ} \mathrm{C}$, which is still within the TNZ.

\section{Thermal neutral zone (TNZ)}

According to the definition, TNZ is the range of ambient temperature at which temperature regulation is achieved only by control of sensible heat loss, ie without regulatory changes in metabolic heat production or evaporative heat loss (IUPS Thermal Commission 1987). Within the TNZ, metabolic rate is independent with Ta.

High and narrow TNZ are typical of desert rodents that avoid extreme temperature fluctuations behaviorally in the thermally buffered microenvironments of their burrows (Downs and Perrin 1994). In this study, the TNZ for Mongolian gerbil was $26-38^{\circ} \mathrm{C}$. For laboratory populations, Robinson (1959) reported that the TNZ extended from 30 to 39 or $40^{\circ} \mathrm{C}$. Luebbert et al. (1979) reported that the $\mathrm{TNZ}$ was $32-34^{\circ} \mathrm{C}$ for $24^{\circ} \mathrm{C}$-acclimated gerbils, $30-36^{\circ} \mathrm{C}$ for $5^{\circ} \mathrm{C}$ -acclimated gerbils and $32-38^{\circ} \mathrm{C}$ for $35^{\circ} \mathrm{C}$-acclimated gerbils. Compared with the above mentioned data, this study indicated that the lower critical temperature is low, whereas the upper critical temperature is similar. However, Weiner and Górecki (1981) found that in wild Mongolian gerbils the TNZ was only about $15-18^{\circ} \mathrm{C}$ and $25^{\circ} \mathrm{C}$ was the lethal temperature. They explained that this is perhaps a metabolic difference between field- and laboratory-bred populations. It is very interesting that the climate characteristics of our research site are somewhat similar to that of Weiner and Górecki (1981). Thus, it is difficult to interpret this great difference between their and our findings.

Bartholomew (1977) stated that high thermal conductance and tolerance of hyperthermia cause the TNZ to move to a higher Ta. This reduces the need for high water loss and large expenditure of energy for cooling at high Ta (Roxburgh and Perrin 1994). Thus, a higher upper critical temperature would be a beneficial adaptation, specifically for water conservation.

\section{Thermoregulation and metabolism}

This study showed that Mongolian gerbils have a high level of metabolism (2.127 $\mathrm{mlO}_{2} \cdot \mathrm{g}^{-1} \cdot \mathrm{h}^{-1}$, ie $72 \%$ higher than predicted value), higher than that previously reported for this species, and are not conformable with the general rule of the thermoregulatory pattern of arid and semi-arid rodent species.

Robinson (1959) found that BMR (calculated from the equation of MR to Ta at the lower end, $30^{\circ} \mathrm{C}$ ) of the Mongolian gerbil was $1.43 \mathrm{mlO}_{2} \cdot \mathrm{g}^{-1} \cdot \mathrm{h}^{-1}$. Luebbert et al. (1979) found that this species is capable of acclimating to a wide range of ambient temperatures and its BMR $\left(1.42 \mathrm{mlO}_{2} \cdot \mathrm{g}^{-1} \cdot \mathrm{h}^{-1}\right)$ is not below that predicted for the body size, even following heat acclimation, significantly differing from the desert 
species. They also found that cold-acclimated gerbils have a significantly higher BMR than non-acclimated controls, increasing to $1.94 \mathrm{mlO}_{2} \cdot \mathrm{g}^{-1} \cdot \mathrm{h}^{-1}$, which is similar to our measurements for newly captured gerbils.

It has been argued that a lower than predicted BMR would be advantageous for animals inhabiting arid areas as it would reduce energy requirements, heat production and evaporative water loss (Borut and Shkolnik 1974). Indeed, many desert mammals have been reported to have a BMR lower than predicted values based on their body mass. Goyal and Ghosh (1983) reported that, among desert rodents, the maximum and average decreases of BMR from expected values were 37 and $16 \%$, respectively, whereas in non-desert rodents, the maximum and average increases of BMR from expected values were 88 and $34 \%$, respectively. A lower than predicted BMR has been reported for desert mammals in all deserts of the world (Degen 1997). A similar conclusion was obtained for the gerbil species (Webb and Skinner 1996). Haim and Harari (1992) suggested that some of the inter-specific variation in BMR within the Gerbillinae might be attributable to inter-specific variation in habitat.

Small mammals from cold deserts are exposed to environmental conditions that differ substantially from those of hot deserts and, in consequence, tend to show different metabolic responses (Degen 1997). Weiner and Górecki (1981) reported that BMR in field-caught gerbils was $1.15 \mathrm{mlO}_{2} \cdot \mathrm{g}^{-1} \cdot \mathrm{h}^{-1}$, close to predicted value and lower than the results of others and ours. This difference is due to, at least in part, the different seasons and different geographic distributions. The relatively low BMR of field-caught gerbils is perhaps because they were summer-acclimatized animals. In summer, the arid steppe of eastern Mongolia is characterized by typical hot desert conditions. Luebbert et al. (1979) showed that heat-acclimated gerbils had a lower BMR than non-acclimated controls.

Various factors have been suggested as determinants of BMR, including body size, phylogeny, climate, and one of the most important, food habits (McNab 1986). The following possible reasons might account for the high metabolic rate of our gerbils: (1) Mongolian gerbils in our studies prefer to live at the interface of farming and grazing (ecotone) and have the habit of storing seeds of grass and crops. Thus, their food is available throughout the year in sufficient abundance to support a high rate of metabolism. (2) Although Mongolian gerbil is a seed-eating rodent, grass leaves and tender stems are their dominant food during spring and summer (Zhou et al. 1988). It has been shown that mammals eating herbs have high basal metabolic rate (McNab 1986). (3) The standard interpretation of low BMRs in desert rodents is that they contribute to water conservation. Therefore, Mongolian gerbils feeding on green vegetation, with its high water and relative low protein contents, might not be required to have low BMR. (4) It is still cold in spring. In April, the mean ambient air temperature is only $2.6^{\circ} \mathrm{C}$ (see Material and methods). The temperature fluctuation between day and night is large. Low temperature could cause animals to increase metabolic rates. (5) Our study site is a semiarid habitat and is different from the hot desert. Animals living here do not have as 
great a need for water conservation as animals inhabiting desert areas, and a reduced metabolic rate is not essential for survival.

\section{Thermal conductance}

In general, desert rodents have conductance lower than expected values based on their body mass. Although the thermal conductance of desert rodents was lower than that of non-desert rodents (Goyal and Ghosh 1983), some of the higher values were reported among the desert rodents and gerbils (Webb and Skinner 1996). Haim and Izhaki (1993) found a significant positive correlation between resting metabolic rate and thermal conductance. Thus, because of the high BMR in our studies, Mongolian gerbils should have slightly higher thermal conductance than predicted. Weiner and Górecki (1981) reported that Mongolian gerbils have a high thermal conductance (regression equation slope between metabolic rates and Tas), and thus different from the results obtained by Robinson (1959) and Luebbert et al. (1979). They found that Mongolian gerbils have moderate thermal coefficients, similar to our results which were slightly higher than predicted values. The higher slope value in Weiner and Górecki's (1981) equation is perhaps because of their narrow Ta range $\left(5-18^{\circ} \mathrm{C}\right)$. Interestingly, all the reports for Mongolian gerbils showed that their thermal conductance is not below the predicted values. Combined with the high higher critical temperature, our results support the prediction of Robinson (1959) that Mongolian gerbils might be active even during summer days. Direct field observations confirmed this conclusion (Agren et al. 1990; D. Wang, pers. obs.). This is also contrary to the observations of Weiner and Górecki (1981).

Mongolian gerbils are reported to have a high level of BMR, a moderate thermal conductance, a lower critical temperature of about $25^{\circ} \mathrm{C}$, a higher upper critical temperature, and a high heat tolerance (Robinson 1959, McManus and Mele 1969, Luebbert et al. 1979). Our results are consistent with these conclusions. This study showed that there is not marked metabolic differences between field and laboratory gerbils. They showed however, somewhat different metabolic properties from hot desert rodents and field-caught Mongolian gerbils studied by Weiner and Górecki (1981).

In conclusion, the characteristics of thermal biology for Meriones unguiculatus are: both BMR and thermal conductance are higher than predicted values based on their body mass, a wide TNZ, low lower critical temperature (although higher than that reported by Weiner and Górecki 1981) and high upper critical temperature all typical adaptive characteristics of both desert and arctic species. Our results support the conclusion of Robinson (1959) that $M$. unguiculatus is not a true desert form. Perhaps extreme severe climate is the main selective force faced by Mongolian gerbils during their evolution with their macroenvironments.

Acknowledgements: We are grateful to Professor W. Zhong and Mr. G. Wang for their kind help. Three anonymous referees are thanked for their constructive comments. This study was supported in part by the National Natural Science Foundation of China (39770122), the Key Projects of Chinese Academy of Sciences (KZ951-B1-106 and KZ952-SI-107), the Foundation of the State Key Laboratory of Integrated Research and Management of Agricultural Pest Insects and Rodents, and the Special Program for Young Scientists of the Chinese Academy of Sciences (STZ-1-05). 


\section{References}

Agren G., Zhong W. and Zhou Q. 1990. Activity pattern in Mongolian gerbils (Meriones unguiculatus) in summer. [In: Reports from the Inner Mongolia Grassland Ecosystem Research Station of Academia Sinica (1979-1988). S. Jiang, Z. Chen and X. Xiao, eds]. Science Press, Beijing: 239-246.

Bartholomew G. 1977. Body temperature and energy metabolism. [In: Animal physiology: principles and adaptations. M. Gordon, ed]. Macmillan Publishing Co., Inc., New York: 364-449.

Borut A. and Shkolnik A. 1974. Physiological adaptations to the desert environment. [In: MTP International Review of Science, Physiology: series 1. Environmental physiology. D. Robertshaw, ed]. Butterworth, London: 185-229.

Bradley S. R. and Deavers D. R. 1980. A re-examination of the relationship between thermal conductance and body weight in mammals. Comparative Biochemistry and Physiology 65A: 463-472.

Bradley W. G. and Yousef M. K. 1972. Small mammals in the desert. [In: Physiological adaptations: desert and mountain. M. K. Yousef, S. M. Horvath and R. W. Bullard, eds]. Academic Press, New York: $127-142$.

Chen Z. 1988. Topography and climate of Xilin River basin. [In: Research on grassland ecosystem. Inner Mongolia Grassland Ecosystem Research Station, Academia Sinica, ed]. Science Press, Beijing: 13-22.

Degen A. A. 1997. Ecophysiology of small desert mammals. Springer, Berlin: 1-296.

Downs C. T. and Perrin M. R. 1994. Comparative aspects of the thermal biology of the short-tailed gerbil, Desmodillus auricularis, and the bushveld gerbil, Tatera leucogaster. Journal of Thermal Biology 19: 385-392.

Goyal S. P. and Ghosh P. K. 1983. Body weight exponents of metabolic rate and minimal thermal conductance in burrowing desert rodents. Journal of Arid Environment 6: 43-52.

Górecki A. 1975. Kalabukhov-Skvortsov respirometer and resting metabolic rate measurement. [In: Methods for ecological energetics. W. Grodziński et al., eds]. Blackwell Scientific, Oxford: 309-313.

Haim A. and Harari J. 1992. A comparative study of heat production and thermoregulation in two sympatric gerbils (Gerbillus gerbillus and G. pyramidum). Israel Journal of Zoology 38: 363-372.

Haim A. and Izhaki I. 1993. The ecological significance of resting metabolic rate and nonshivering thermogenesis for rodents. Journal of Thermal Biology 18: 71-81.

Hayssen V. and Lacy R. C. 1985. Basal metabolic rates in mammals: taxonomic differences in the allometry of BMR and body mass. Comparative Biochemistry and Physiology 81A: 741-754.

Herreid C. F. and Kessel B. 1967. Thermal conductance in birds and mammals. Comparative Biochemistry and Physiology 21: 405-414.

IUPS Thermal Commission 1987. Glossary of terms for thermal physiology. Pflugers Archives 410: 567-587.

Kleiber M. 1961. The fire of life: An introduction to animal energetics. Wiley, New York: 1-454.

Luebbert S. J., McGregor L. E. and Roberts J. C. 1979. Temperature acclimation in the Mongolian gerbil Meriones unguiculatus: changes in metabolic rate and the response to norepinephrine. Comparative Biochemistry and Physiology 63A: 169-175.

McManus J. J. and Mele J. A. 1969. Temperature regulation in the Mongolian gerbil, Meriones unguiculatus. Bulletin of the New Jersey Academy of Sciences 14: 21-22.

McNab B. K. 1980. On estimating thermal conductance in endotherms. Physiological Zoology 53: $145-156$.

McNab B. K. 1986. The influence of food habits on the energetics of eutherian mammals. Ecological Monographs 56: 1-19.

Robinson P. F. 1959. Metabolism of the gerbil, Meriones unguiculatus. Science 130: 502-503.

Roxburgh L. and Perrin M. R. 1994. Temperature regulation and activity pattern of the round-eared elephant shrew Macroscelides proboscideus. Journal of Thermal Biology 19: 13-20.

SPSS for Windows 1988. Publishing House of Electronics Industry, Beijing: 1-509. 
Walker E. P. 1968. Mammals of the World. 2nd edition. Johns Hopkins Press, Baltimore: 1-644.

Webb P. I. and Skinner J. D. 1996. Physiological adaptation to aridity in the bushveld gerbil, Tatera leucogaster. Journal of Zoology, London 238: 693-701.

Weiner J. and Górecki A. 1981. Standard metabolic rate and thermoregulation in five species of Mongolian small mammals. Journal of Comparative Physiology B 145: 127-132.

Zhou Q., Zhong W., Sun C. and Wang G. 1988. Zoogeographical characteristics of mammals in Baiyinxile area. Research on Grassland Ecosystem 3: 269-275. [In Chinese with English summary]

Received 14 April 1999, accepted 6 October 1999 